\title{
EDITORIAL
}

\section{A short message from the Editor-in-Chief: Submit articles for academic advancement or contribute to}

evidence pool and education

\section{Dear Readers}

This is an unannounced editorial; despite we promised to give a platform for our international editors I decided to write myself to answer the rhetoric question addressed by junior researchers and clinicians - Does your journal have impact factor? To submit or not submit? As per our weekly update of journal's website access, the access and downloads of articles from different continents and countries and cities from all over the world has been constantly growing since the first launch of our website. However, there is also some reluctance in submission of unsolicited articles, as I would expect as an editor-in-chief.

Analyzing this discordance, there might be several explanations. The authors tend to submit articles to advance their careers, earn degrees - in this case their primary decisive factor would be the journals with impact factor (Clarivate - former Thomson Scientific) or publishing in databases that provide alternative citation metrics (Scopus) $(1,2)$. Citation metrics indices are important and actually were not invented for evaluating scientific productivity of researchers (Hirsch index is one of the appropriate indices), but rather aimed at evaluation of journals' productivity (3). Impact factor per se is not also a perfect measure of science, as there is a much debate on the topic that also has been acknowledged by the organizations providing these metrics and they developed more sophisticated indexes in evaluation of journals 'performance.

On the other hand, the survey studies conducted among junior and senior researchers, demonstrated that junior researchers prefer submission to journals with high impact factor, as the low IF journals "will not look good in their CVs" and senior researchers perception - "current science is based on impact factors" (4).

Without diminishing importance of scientific productivity metrics used for grading journals' performance, we should also emphasize here that articles in biomedical publications form evidence pool for systematic reviews and metaanalyses that in fact summarize evidence and provide the tools for creating recommendations for clinical practice guidelines - that is called in other ways evidence-based medicine. Even case reports can contribute to evidence-based medicine or define the directions for research. As an author and researcher, I have not noticed yet, while reading meta-analyses or guidelines that provide the methodology of evidence collection - notion that evidence was collected only from journals with impact factors and evidence collection is usually performed from databases like PUBMED or EMBASE that include also journals without impact factors.

There is no such a study yet seeking the answer for the question, effect of articles collection from journals with no impact factor, low impact factor or high impact factor on results of metaanalysis. It is also known that high-impact factor journals' usually publish the randomized controlled trials (RCTs) with better methodological quality than low impact factor journals, at the same time the high impact factor is not associated with the publication of RCTs with significant outcome (5).

Our journal is the peer-reviewed open access journal, that provides the opportunity to read and download articles for free with the restrictions for only personal use and citing the source. Open access journals provide opportunity for scientists from different countries, developed and developing in terms of access to internet, to form a platform for exchange of opinions and scientific results (6). It is also worth mentioning that our journal is in process of applications to various international databases, to increase its visibility and provide the opportunity for research articles and case reports enter the international evidence pool. 
The international databases, with or without citation metrics, collect information even from non-indexed yet journals. That is why for the most desperate junior researchers seeking the impact factor or other metrics journals, your contribution will be indexed in future and even cited as it is already in the knowledge pool, once our journal officially will be indexed in those databases required for your academic advancement. One should keep in mind, that every your clinical case report or research might be found interesting or contain some rare knowledge that your colleagues throughout the world can use and take in account in their research or clinical practice as well.

Let me remind, we implement unbiased doubleblind peer-review by international experts without discrimination of country of origin or implement principle of unbiased evaluation.

I hope I answered the rhetoric question and we as editors look forward for your contributions and discussions.

\section{Gulmira Kudaiberdieva} Editor-in-Chief

Heart Vessels and Transplantation $31^{\text {st }}$ July 2017

Peer-review: Internal

Conflict of interest: None to declare.

Authorship: G.K.

Acknowledgment and funding: None to

declare.

\section{References}

1.Kamerlin SC. Hypercompetition in biomedical research evaluation and its impact on young scientist careers. Int Microbiol 2015; 18: 253-61. 2.Azer SA, Holen A, Wilson I, Skokauskas N. Impact factor of medical education journals and recently developed indices: Can any of them support academic promotion criteria? J Postgrad Med 2016; 62: 32-9.

3.The PLoS Medicine Editors. the impact factor game. It is time to find a better way to assess the scientific literature. PLoS Med 2006; 3: e291.

4.Tijdink JK, Schipper K, Bouter LM, Maclaine Pont $\mathrm{P}$, de Jonge $\mathrm{J}$, et al. How do scientists perceive the current publication culture? A qualitative focus group interview study among Dutch biomedical researchers. BMJ Open 2016; 6: e008681.

5. Ahmed Ali U, Reiber BMM, Ten Hove JR, van der Sluis PC, Gooszen HG, Boermeester MA, et al. Journal impact factor and methodological quality of surgical randomized controlled trials: an empirical study. Langenbecks Arch Surg 2017 Jun 4. doi: 10.1007/s00423-017-1593-6.

6 . John Wilbanks. Another reason for opening access to research. BMJ 2006; 333: 1306-8. 